\title{
The Kite Latissimus Dorsi Flap for Breast Reconstruction: An Attempt to Reduce Lateral Chest Wall Deformity and Axillary Bulking
}

\author{
J. Correia Anacleto ${ }^{1,2}$ - C. Mavioso ${ }^{1,2}$ - P. F. Gouveia ${ }^{1}$ A. Magalhães ${ }^{2}$. \\ J. Bastos Martins ${ }^{3} \cdot$ A. Moura $^{2}$ - D. Pinto ${ }^{1}$ - M. J. Cardoso ${ }^{1}$
}

Received: 4 February 2016/Accepted: 25 May 2016

(C) Springer Science+Business Media New York and International Society of Aesthetic Plastic Surgery 2016

\begin{abstract}
The latissimus dorsi flap is a commonly used tissue transfer for volume replacement in partial or total breast reconstruction. In this era of cosmetic awareness and oncoplastic breast surgery, two main defects are related to the conventional technique: the back scar and the bulkiness on the lateral chest wall, under the axilla. Axillary bulking, a disturbing defect for the majority of patients, is a persistent consequence, independent of the technique used, even when the proximal tendon is cut. We describe a new approach, the kite latissimus dorsi flap, consisting of harvesting the flap, partially or totally, with pedicle dissection from the muscle, extending dissection, perforator style if needed, until the external border of the breast (anterior axillary line) is reached. The muscle is then cut at that level, leaving no unnecessary volume under the axilla, which would cause bulkiness and chest wall deformity.

Level of Evidence $V$ This journal requires that authors assign a level of evidence to each article. For a full description of these Evidence-Based Medicine ratings, please refer to the Table of Contents or the online Instructions to Authors www.springer.com/00266.
\end{abstract}

Keywords Latissimus dorsi flap - Lateral chest wall deformity $\cdot$ Breast reconstruction · Axillary bulking

$\triangle$ J. Correia Anacleto

joao.anacleto@fundacaochampalimaud.pt

1 Champalimaud Clinical Center, Breast Unit, Champalimaud Foundation, Av. Brasilia, 1400-038 Lisbon, Portugal

2 Hospital da Trindade, Porto, Portugal

3 Plastic Reconstructive Surgery Departement, Hospital Sao Jose, Lisbon, Portugal
The latissimus dorsi (LD) flap, first described by Tansini in 1896 [1], is a commonly used tissue transfer for volume replacement in breast reconstruction, either for partial or total mastectomy defects.

In this era of cosmetic awareness and oncoplastic breast surgery, the conventional technique presents two main concerns: the large back scar and the bulkiness on the lateral chest wall, under the axilla [2].

Trying to improve aesthetic results, harvesting has been addressed in several ways, from shortening the scar to the endoscopic approach, with less traumatic tissue dissection and improved cosmesis [3-6].

Lateral chest wall deformities have not been so widely thought of, although the resulting defect, independent of the technique used, even when the proximal tendon is cut, can be quite disturbing for many patients.

We describe a new approach, the kite latissimus dorsi flap (kLD), that consists of harvesting the muscle, with pedicle dissection from itself, perforator flap style if needed, until the external limit of the breast to be reconstructed (anterior axillary line). (Fig .1).

The muscle is then cut at that level, leaving no unnecessary volume under the axilla.

An axillary incision is used and initial dissection focuses on identifying the thoracodorsal axis. Once identified, minor vascular tributaries and the constant branch for the tip of the scapula are ligated and divided, to permit flap rotation; vascular dissection is carried out until the pedicle enters the muscle belly (Fig. 2).

Dissection continues in the upper and outer portion of the muscle to identify its posterior edge, where it is split from the teres major; then, the deep surface of the muscle's upper part is elevated, to separate the entire muscle from its upper attachments, just above where the dissected pedicle enters the muscle. Immediately after, the deep surface of 


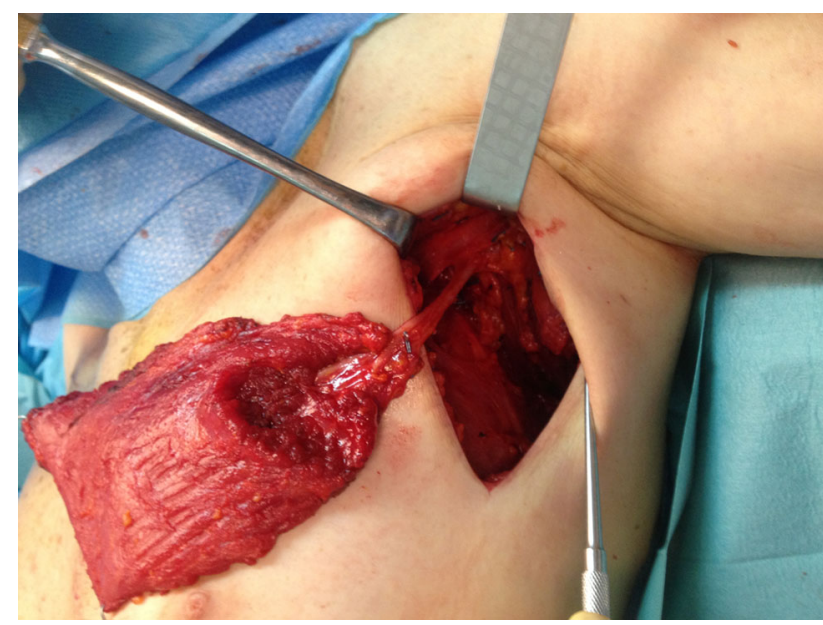

Fig. 1 Kite latissimus dorsi flap — positioned flap without volume on lateral chest wall

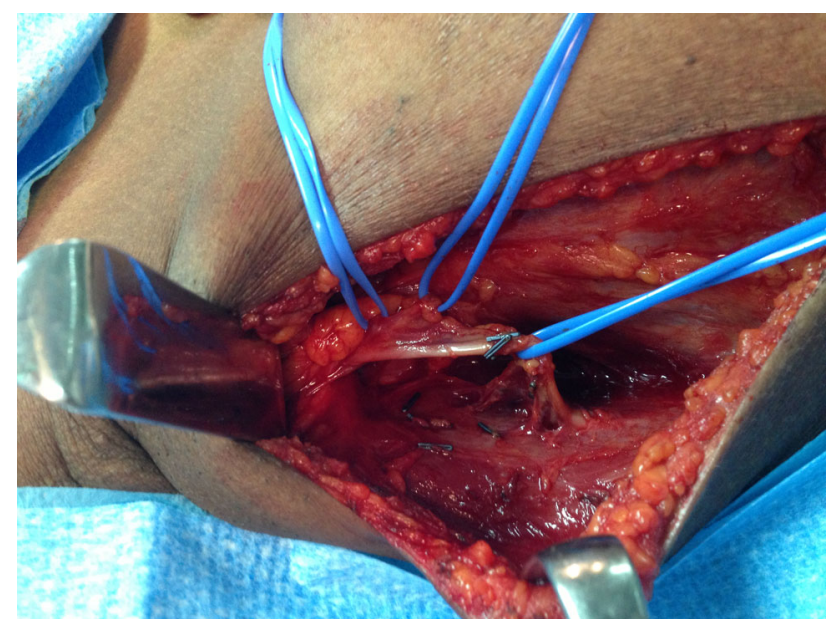

Fig. 2 Thoracodorsal vessels dissected to the muscle

the $\mathrm{kLD}$ is elevated off the chest wall using a combination of electrocautery and blunt dissection, assisted with a lighted retractor; thoracolumbar perforators are identified and ligated.

The next step is to dissect the superficial plane, using electric cautery, again assisted with a lighted retractor. After completing the deep and superficial dissection planes, we reach a point in the procedure where the $\mathrm{kLD}$ is left adherent to only its distal origins and its proximal insertion on the humerus.

The distal extent of the muscular flap is sharply divided using tactile guidance and traction, and electrocautery.

After distal division is complete, the muscle is delivered through the axillary incision, now only adherent to its proximal origin.

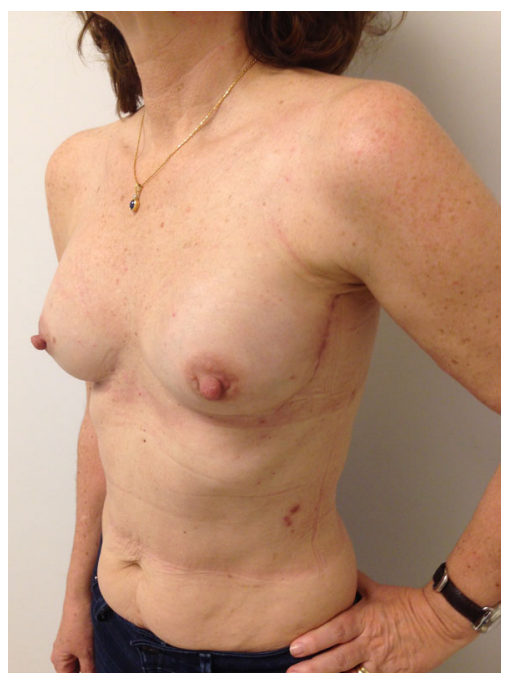

Fig. 3 Aesthetic result at 3 months postop

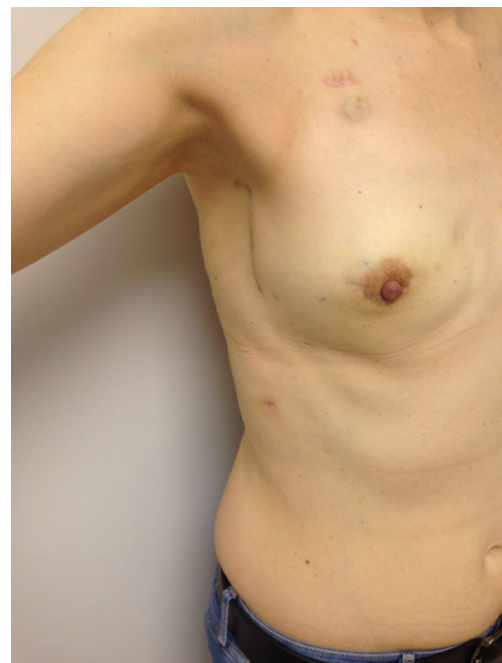

Fig. 4 Aesthetic result at 6 months postop

The distance to the lateral breast edge is then calculated and if necessary, further pedicle dissection is carried into the muscle, perforator style, or the serratus branch is ligated, permitting the LD muscle belly not to cross the lateral chest wall; then the upper muscle is again cut using electrocautery, and the muscle flap is transferred. We have used this new approach in 100 patients, with no significant complications, an irrelevant increase in operating time (around $15 \mathrm{~min}$ ), and believe that this modification will improve lateral chest wall cosmesis (Figs. 3, 4) Studies will be needed to evaluate aesthetic results, and this will be our next step.

\section{Compliance with Ethical Standards}

Conflicts of Interest The authors declare that they have no conflicts of interest to disclose. 


\section{References}

1. Champaneria MC, Wong WW, Hill ME, Gupta SC (2012) The evolution of breast reconstruction: a historical perspective. World $\mathrm{J}$ Surg 36(4):730-742

2. Gerber B, Krause A, Reimer T, Müller H, Friese K (1999) Breast reconstruction with latissimus dorsi flap: improved aesthetic results after transection of its humeral insertion. Plast Reconstr Surg 103(7):1876-1881

3. Missana MC, Pomel C (2007) Endoscopic latissimus dorsi flap harvesting. Am J Surg 194(2):164-169
4. Chung JH, You HJ, Kim HS, Lee BI, Park SH, Yoon ES (2015) A novel technique for robot assisted latissimus dorsi flap harvest. J Plast Reconstr Aesthet Surg 68(7):966-972

5. Kim H, Wiraatmadja ES, Lim SY, Pyon JK, Bang SI, Oh KS, Lee JE, Nam SJ, Mun GH (2013) Comparison of morbidity of donor site following pedicled muscle-sparing latissimus dorsi flap versus extended latissimus dorsi flap breast reconstruction. J Plast Reconstr Aesthet Surg 66(5):640-646

6. Leckenby J, Butler D, Grobbelaar A (2015) The axillary approach to raising the latissimus dorsi free flap for facial re-animation: a descriptive surgical technique. Arch Plast Surg 42(1):73-77 